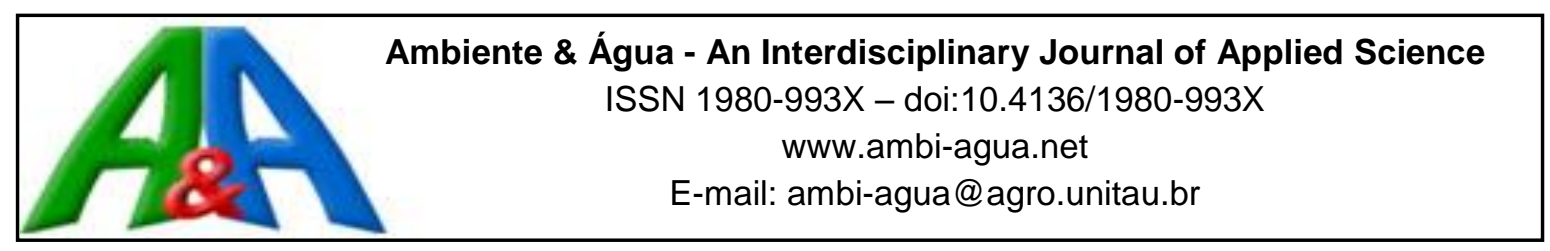

\title{
Caracterização e modelagem de indicadores de qualidade ambiental urbana integrada e aplicação à Vila Habitacional União, bairro da Terra Firme, Belém, Pará
}

\author{
doi: 10.4136/ambi-agua.1372
}

Received: 16 Aug. 2013; Accepted: 08 Dec. 2013

\author{
Francisco de Assis Cruz Melo $^{1,2^{*}}$; Mariko Ueno ${ }^{1}$ \\ ${ }^{1}$ Universidade de Taubaté (UNITAU), SP \\ Programa de Pós-graduação em Ciências Ambientais \\ ${ }^{2}$ Secretaria Municipal de Educação, Belém, PA \\ *Autor correspondente: e-mail: ssaisemelo@yahoo.com.br, \\ maritieue@gmail.com
}

\section{RESUMO}

O espaço urbano de Belém, Pará, apresenta problemas ambientais que impõem, à grande parte da população, uma qualidade ambiental urbana crítica. O presente estudo objetivou avaliar a qualidade ambiental urbana da vila habitacional União, bairro da Terra Firme, Belém, Pará. A metodologia estruturou o índice de qualidade ambiental urbana integrada, a partir da modelagem de indicadores de qualidade ambiental urbana, habitabilidade urbana e qualidade da água tratada. Esses três índices quantificaram as variáveis de abastecimento de água, coleta de lixo, cobertura vegetal, esgotamento sanitário, pavimentação de vias, condições de infraestrutura dos domicílios, existência de equipamentos urbanos de uso comum, transporte coletivo, acessibilidade, renda familiar, condições empregatícias, escolaridade e qualidade da água tratada. Delimitou-se a zona de habitabilidade urbana para a espacialização das variáveis utilizadas. Os resultados dos indicadores são: índice de qualidade ambiental urbana, 50 pontos, nível regular de qualidade ambiental; índice de habitabilidade urbana, 48,6 pontos, nível regular de habitabilidade e índice de qualidade da água tratada, 98,13 pontos, nível ótimo de qualidade da água. A média aritmética dos três índices gerou o índice de qualidade ambiental urbana integrada, 65,57 pontos, nível bom de qualidade ambiental da vila habitacional União. A interpretação deste índice integrado reflete os indicadores mensurados em cada índice. Conclui-se que a modelagem de indicadores de qualidade ambiental urbana representa a possibilidade do uso de uma importante ferramenta nas análises da qualidade ambiental urbana, em micro ou em macro escala, propondo-se relações de gestão e reestruturação mais eficientes do ambiente urbano, principalmente nas periferias urbanas.

Palavras-chave: vila habitacional, qualidade ambiental urbana, indicadores ambientais.

\section{Characterization and modeling of urban environmental quality indicators}

\begin{abstract}
Environmental problems in the urban area of Belém, Pará, Brazil, deny a large portion of the population critical environmental quality. The present study evaluated the environmental quality of the urban village of União, in a neighborhood called Terra Firme, Belém, Pará. An
\end{abstract}


integrated urban environmental quality index was proposed, based on the modeling of indicators of urban environmental quality, urban livability and quality of treated water. These three indices encompass the variables of water supply, garbage collection, vegetation, sewage, road paving, infrastructure condition of households, the existence of urban equipment for common use, public transport, accessibility, family income, employment conditions, education and quality of treated water. The results of the indicators are: urban environmental quality index, 50.0 points (indicating a regular level of environmental quality); urban livability index, 48.6 points (representing moderate level of livability); and quality index of the treated water, 98.1 points (which is an optimal level of water quality). The arithmetic average of the three indices generated an integrated urban environmental quality of 65.6 points, a good environmental quality level of the urban village housing in União. The interpretation of this integrated index reflects the indicators measured in each index. We conclude that the modeling of urban environmental quality indicators was an important tool for the analysis of urban environmental quality in micro or macro scales, and this allowed us to propose more efficient management and restructuring of the urban environment.

Keywords: village housing, environmental indicators, urban settlement.

\section{INTRODUÇÃO}

O bairro da Terra Firme, Belém, Pará, na condição de periferia, constitui uma face contraditória do espaço intraurbano de Belém, e sua dinâmica define-se pela manifestação de impactos socioespaciais e ambientais que se refletem nas tipologias de ocupação urbana, entre elas, a vila habitacional, configurando-se como assentamento urbano que se proliferou nas cidades brasileiras, apresentando dinâmica e características expressas na forma de organização socioespacial intraurbana da população de baixa renda, que encontra, como alternativa ao déficit habitacional, moradias que atendem às suas necessidades mínimas de habitação (Kohara, 2009).

O quadro atual das grandes cidades brasileiras é composto por partes radicalmente heterogêneas e constituídas por conjuntos de segmentos sociais distintos, onde os ricos vivem isolados por imensos muros, grades e segurança própria, enquanto os pobres vivem segregados e marginalizados, sobretudo ocupando áreas sem infraestrutura e longe do alcance dos equipamentos urbanos e comunitários, ou seja, em áreas precárias, que contradizem o desenvolvimento urbano, despertando conflitos de ordem urbana, social, gerencial e estética, aspectos estes que são sinônimos de exclusão, degradação, segregação e marginalidade socioespacial (Polli, 2006).

Assim, qualidade ambiental nos estudos sobre as cidades analisa a ocupação desordenada dos assentamentos urbanos, a instalação exponencial da atividade industrial, o adensamento da frota automotiva, a ampliação dos rejeitos sólidos e líquidos e a redução das áreas verdes, fatores que aprofundam ainda mais as desigualdades (Minaki e Amorim, 2007).

\section{MATERIAL E MÉTODOS}

\subsection{Caracterização da área de estudo}

O estudo foi realizado na vila habitacional União, bairro da Terra Firme, localizado na zona sul de Belém (Figura 1), no período de janeiro a julho de 2012. 


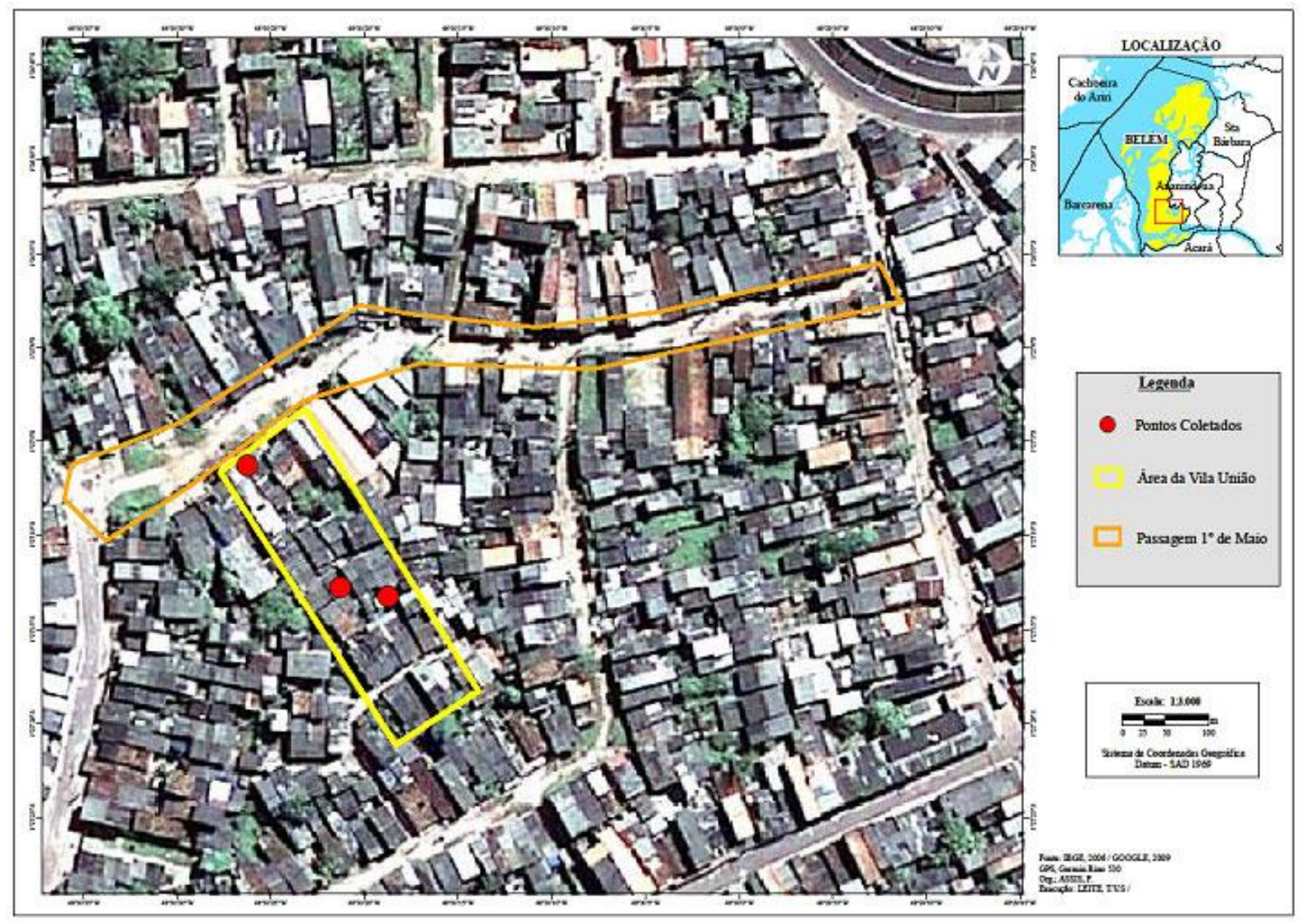

Figura 1. Localização da vila habitacional União, Bairro da Terra Firme, Belém, Pará. Fonte: IBGE ( 2008).

\subsection{Procedimento metodológico}

O estudo baseou-se no índice de qualidade ambiental urbana (Dias, 2011), no índice de habitabilidade urbana (Florianópolis, 2007) e no índice de qualidade da água tratada (Brasil, 2006). A integração desses índices considerou os estudos de Nahas (2000), Moraes; Santos; Sampaio (2006), Rocha (2008) e Dias (2011), para estabelecimento do índice de qualidade ambiental urbana integrada (IQAUI), conforme Tabela 1.

Tabela 1. Descritor do índice de qualidade ambiental urbana integrada (IQAUI).

\begin{tabular}{l|c|c|c}
\hline \multicolumn{3}{c}{ Índice de Qualidade Ambiental Urbana Integrada } \\
\hline Índices & Cálculos dos Índices & $\begin{array}{c}\text { Composição dos } \\
\text { Índices }\end{array}$ & IQAUI \\
\hline $\begin{array}{l}\text { Índice de Qualidade } \\
\text { Ambiental Urbana }\end{array}$ & $\begin{array}{c}\mathrm{IQAU}= \\
\mathrm{IaPa}+\mathrm{IbP}+\mathrm{IcPc}+\mathrm{IdPd}+\mathrm{IePe}\end{array}$ & & \\
\cline { 1 - 2 } $\begin{array}{l}\text { Índice de Habitabilidade } \\
\text { Urbana }\end{array}$ & $\frac{I C M+I Q E U+I S E C}{3}$ & $\left(\frac{I Q A U+I H U+I Q A T}{3}\right)$ & 100 \\
\cline { 1 - 2 } $\begin{array}{l}\text { Índice de Qualidade da } \\
\text { Água Tratada }\end{array}$ & $\left(\frac{I C+I B+I F Q}{3}\right)$ & & \\
\hline
\end{tabular}

O sistema de pontuação do índice de qualidade ambiental urbana integrada (IQAUI) é especificado no Quadro 1. 
Quadro 1. Pontuação do índice de qualidade ambiental urbana integrada.

\begin{tabular}{|ccc|}
\hline Classe de IQAUI & Valor do IQAUI & Nível de qualidade \\
\hline A & $85-100$ & Ótimo \\
B & $65-85$ & Bom \\
C & $50-65$ & Intermediário (Regular) \\
D & $25-50$ & Ruim \\
E & $0-25$ & Péssimo \\
\hline
\end{tabular}

Fonte: Adaptado de Dias (2011).

\subsubsection{Descrição do Índice de Qualidade Ambiental Urbana}

O IQAU (Dias, 2011) é especificado no Quadro 2. Para o cálculo dos indicadores, empregou-se ZHU: zona de habitabilidade urbana; P: peso do respectivo índice parcial; pn: fator de peso atribuído para o tipo de disposição do esgoto (Quadro 3). Os índices parciais expressam o estado do indicador avaliado. $\mathrm{O}$ indicador cujo índice obtido é zero corresponde à pior avaliação, enquanto o índice 1 é aplicado à melhor avaliação.

$\mathrm{O}$ índice de qualidade ambiental urbana (IQAU) resulta da soma dos indicadores parciais correspondentes multiplicados pelo seu respectivo peso. Já o índice de esgotamento sanitário resulta do somatório das médias ponderadas para cada tipo de disposição.

Quadro 2. Descritor do índice de qualidade ambiental urbana.

\begin{tabular}{|c|c|c|c|c|c|}
\hline \multicolumn{6}{|c|}{ Índice de Qualidade Ambiental Urbana } \\
\hline Indicadores & Cálculos dos Indicadores & $\begin{array}{l}\text { Índices } \\
\text { parciais }\end{array}$ & Peso & $\begin{array}{c}\text { Composição } \\
\text { dos } \\
\text { Indicadores }\end{array}$ & IQAU \\
\hline $\begin{array}{l}\text { Abastecimento de água } \\
\text { (Iabs) }\end{array}$ & Iabs $=\left(\frac{\text { Domicílios ligados a rede }}{\text { total de domicílios }}\right)$ & $0-1$ & 15 & & \\
\hline $\begin{array}{l}\text { Cobertura Vegetal } \\
\qquad(I c v)\end{array}$ & $I c v=\left(\frac{\text { Área veg. } n a Z H U}{\text { Área total } Z H U}\right)$ & $0-1$ & 15 & & \\
\hline $\begin{array}{l}\text { Esgotamento sanitário } \\
\text { (Ies) }\end{array}$ & Ies $=\frac{p 1 t 1+p 2 t 2+\cdots p n t n}{p 1+p 2+}$ & $0-1$ & 35 & $\begin{array}{c}\mathrm{IQAU}= \\
\mathrm{IaPa}+\mathrm{IbPb}+\mathrm{Ic} \\
\mathrm{Pc}+\mathrm{IdPd}+\mathrm{IeP}\end{array}$ & 100 \\
\hline $\begin{array}{l}\text { Limpeza pública } \\
\text { urbana } \\
\text { (Ilpu) }\end{array}$ & $\begin{array}{l}\text { Ilpu } \\
=\left(\frac{\text { Domicílios atendidos pela coleta de lixo }}{\text { total de domicílios }}\right)\end{array}$ & $0-1$ & 20 & $\mathrm{e}$ & \\
\hline $\begin{array}{l}\text { Pavimentação das ruas } \\
\text { (Ipav) }\end{array}$ & $I p a v=\left(\frac{\text { Extensão das vias pav. }}{\text { Total de vias }}\right)$ & $0-1$ & 15 & & \\
\hline
\end{tabular}

Fonte: Adaptado de Dias (2011).

Quadro 3. Formas de disposição/afastamento dos esgotos e o respectivo peso de cada uma na avaliação da qualidade ambiental.

\begin{tabular}{|lc|}
\hline Forma de disposição/afastamento dos esgotos & Peso \\
\hline Rede de esgoto com tratamento posterior & 1,0 \\
Rede de esgotos ou drenagem sem tratamento posterior & 0,5 \\
Fossa séptica com sumidouro ou ligada à drenagem & 0,4 \\
Fossa rudimentar & 0,2 \\
Vala de infiltração ou outro escoadouro & 0,1 \\
Sem dispositivo de afastamento & 0,0 \\
\hline
\end{tabular}

Fonte: Dias (2011). 
O sistema de pontuação do índice de qualidade ambiental é ilustrado no Quadro 4.

Quadro 4. Pontuação do Índice de qualidade ambiental urbana.

\begin{tabular}{|c|c|c|}
\hline Classe de IQAU & Valor do IQAU & Nível de qualidade \\
\hline A & $85-100$ & Ótimo \\
B & $65-85$ & Bom \\
C & $50-65$ & Intermediário (Regular) \\
D & $25-50$ & Ruim \\
E & $0-25$ & Péssimo \\
\hline
\end{tabular}

Fonte: DIAS (2011).

\subsubsection{Descrição do Índice de Habitabilidade Urbana}

O Índice de Habitabilidade urbana (IHU) é dado pela média aritmética de 3 indicadores: indicador de condições de moradia (ICM), indicador de qualidade dos espaços urbanos (IQEU) e indicador socioeconômico-cultural (ISEC), conforme Quadro 5.

Quadro 5. Síntese do índice de habitabilidade urbana.

\begin{tabular}{|c|c|c|c|c|c|c|}
\hline \multicolumn{7}{|c|}{ Índice de Habitabilidade Urbana } \\
\hline \multirow{2}{*}{\multicolumn{2}{|c|}{ Indicadores }} & \multirow{2}{*}{ Variáveis } & \multicolumn{2}{|c|}{ Cálculos } & \multirow{2}{*}{$\begin{array}{l}\text { Composição dos } \\
\text { Indicadores }\end{array}$} & \multirow{2}{*}{$\begin{array}{l}\text { Pontuação de } \\
\text { IHU }\end{array}$} \\
\hline & & & Variáveis & Indicadores & & \\
\hline \multirow{5}{*}{$\begin{array}{l}\text { Indicador } \\
\text { de condição } \\
\text { de moradia } \\
\text { (ICM) }\end{array}$} & \multirow{3}{*}{$\begin{array}{l}\text { Indicador de } \\
\text { Qualidade } \\
\text { Arquitetônica } \\
\text { (IQAr) }\end{array}$} & Adequação projetual & \multirow{3}{*}{$\frac{A p+A g+D o}{3}$} & \multirow{5}{*}{$\frac{I Q A r+I Q T}{2}$} & \multirow{18}{*}{$\begin{array}{c}\begin{array}{c}I C M+I Q E U \\
+I S E C\end{array} \\
3\end{array}$} & \multirow{18}{*}{100} \\
\hline & & Aglomeração & & & & \\
\hline & & Densidade ocupacional & & & & \\
\hline & \multirow{2}{*}{$\begin{array}{l}\text { Indicador de } \\
\text { Qualidade } \\
\text { Técnica } \\
\text { (IQT) }\end{array}$} & Material adequado & \multirow{2}{*}{$\frac{M a+H u}{2}$} & & & \\
\hline & & $\begin{array}{c}\text { Presença de sinais de } \\
\text { umidade }\end{array}$ & & & & \\
\hline \multirow{6}{*}{$\begin{array}{l}\text { Indicador } \\
\text { de } \\
\text { qualidade } \\
\text { dos espaços } \\
\text { urbanos } \\
\text { (IQEU) }\end{array}$} & \multirow{2}{*}{$\begin{array}{l}\text { Indicador de } \\
\text { equipamentos } \\
\text { urbanos } \\
\text { (IEC) }\end{array}$} & $\begin{array}{l}\text { Existência de } \\
\text { equipamentos de uso } \\
\text { comum }\end{array}$ & \multirow{2}{*}{$\frac{E q c+M l}{2}$} & \multirow{6}{*}{$\frac{\begin{array}{l}I E C+I D C+ \\
I M U A F\end{array}}{3}$} & & \\
\hline & & $\begin{array}{c}\text { Manutenção e limpeza } \\
\text { dos espaços e } \\
\text { equipamentos de uso } \\
\text { comum }\end{array}$ & & & & \\
\hline & $\begin{array}{l}\text { Indicador de } \\
\text { defesa civil }\end{array}$ & $\begin{array}{l}\text { Unidades sem acesso a } \\
\text { serviços de utilidade } \\
\text { pública }\end{array}$ & $A u p+R f$ & & & \\
\hline & (IDC) & $\begin{array}{l}\text { Unidades em áreas de } \\
\text { risco }\end{array}$ & & & & \\
\hline & $\begin{array}{c}\text { Indicador de } \\
\text { mobilidade } \\
\text { urbana e } \\
\text { acessibilidade }\end{array}$ & $\begin{array}{c}\text { Existência de } \\
\text { rebaixamento das guias } \\
\text { de calçadas em } \\
\text { travessias. }\end{array}$ & \multirow{2}{*}{$\frac{E r+T c}{2}$} & & & \\
\hline & $\begin{array}{c}\text { física } \\
\text { (IMUAF) }\end{array}$ & $\begin{array}{l}\text { Localidade atendida } \\
\text { pelo transporte coletivo }\end{array}$ & & & & \\
\hline \multirow{7}{*}{$\begin{array}{c}\text { Indicador } \\
\text { Socioeconô } \\
\text { mico- } \\
\text { cultural } \\
\text { (ISEC) }\end{array}$} & & $\begin{array}{c}\text { Acesso de jovens de } 7 \text { a } \\
14 \text { anos a educação } \\
\text { básica }\end{array}$ & & \multirow{7}{*}{$\begin{array}{c}I E+I E L+ \\
\frac{I E R+I S}{4}\end{array}$} & & \\
\hline & $\begin{array}{l}\text { Indicador de } \\
\text { Educação } \\
\text { (IE) }\end{array}$ & $\begin{array}{c}\text { Acesso de jovens de } 15 \\
\text { a } 17 \text { anos a programas } \\
\text { de profissionalização }\end{array}$ & $\frac{A c+C p+E c}{3}$ & & & \\
\hline & & $\begin{array}{c}\text { Escolaridade do chefe } \\
\text { de família }\end{array}$ & & & & \\
\hline & $\begin{array}{l}\text { Indicador de } \\
\text { Esporte Lazer } \\
\text { (IEL) }\end{array}$ & - & - & & & \\
\hline & \multirow{2}{*}{$\begin{array}{l}\text { Indicador de } \\
\text { Emprego e } \\
\text { Renda } \\
\text { (IER) }\end{array}$} & $\begin{array}{l}\text { Domicílios com mulher } \\
\text { chefe de família }\end{array}$ & $M c+S c$ & & & \\
\hline & & $\begin{array}{l}\text { Situação empregatícia } \\
\text { da família }\end{array}$ & 2 & & & \\
\hline & $\begin{array}{l}\text { Indicador de } \\
\text { Saúde } \\
\text { (IS) }\end{array}$ & - & - & & & \\
\hline
\end{tabular}

Fonte: Adaptado de Florianópolis (2007). 
No Quadro 6 descreve-se o sistema de pontuação do índice de habitabilidade urbana.

Quadro 6. Pontuação do índice de habitabilidade urbana.

\begin{tabular}{|c|c|c|}
\hline $\begin{array}{l}\text { Pontuação } \\
\text { IHU }\end{array}$ & $\begin{array}{c}\text { Situação de } \\
\text { Habitabilidade Urbana }\end{array}$ & Características \\
\hline 0 a 30 & Habitabilidade Crítica & $\begin{array}{l}\text { Apresenta sinais negativos preponderantes em relação ao atendimento da } \\
\text { manutenção das condições internas e externas a capacidade de ser } \\
\text { habitado. }\end{array}$ \\
\hline 31 a 50 & Habitabilidade Regular & $\begin{array}{c}\text { Condições existentes chegam a atender a maioria dos itens mínimos para } \\
\text { a sustentabilidade dos fatores descritos. }\end{array}$ \\
\hline 51 a 70 & Habitabilidade Boa & Poucos aspectos a serem melhorados \\
\hline 71 a 100 & Habitabilidade Ótima & $\begin{array}{l}\text { Condições adequadas internas e externas ao domicílio, eficiência nos } \\
\text { serviços de infraestrutura, equipamentos e programas sociais e demais } \\
\text { condições que afetam as condições de sustentabilidade socioeconômica } \\
\text { cultural de proteção e preservação ambiental, associado a dispositivos } \\
\text { legais que asseguram a regularização da propriedade do domicílio. }\end{array}$ \\
\hline
\end{tabular}

Fonte: Florianópolis (2007).

\subsubsection{Descrição do Índice de Qualidade da Água Tratada (IQAT)}

O IQAT é calculado pela média aritmética de 3 outros indicadores (Brasil, 2006) (Quadro 7).

Quadro 7. Descritor do índice de qualidade da água tratada (IQAT).

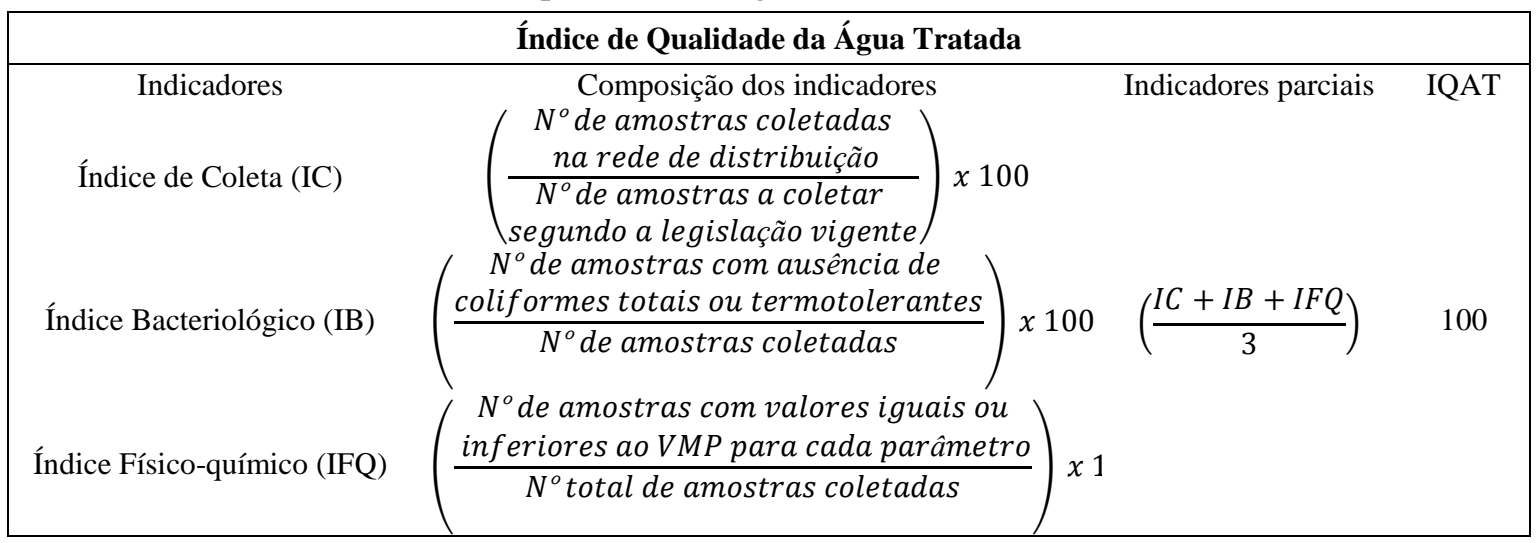

Fonte: Brasil (2006).

No Quadro 8 verifica-se o sistema de pontuação para a avaliação da qualidade da água tratada.

Quadro 8. Pontuação do índice de qualidade da água tratada.

\begin{tabular}{|cclcc|}
\hline Classe & Valor & \multicolumn{1}{c}{ Características } & $\begin{array}{c}\text { Nível de } \\
\text { qualidade }\end{array}$ \\
A & $80-100$ & $\begin{array}{l}\text { Condições adequadas de potabilidade da água seguindo integralmente os } \\
\text { padrões estabelecidos pelo MS e MMA em suas resoluções e portarias. } \\
\text { Poucos aspectos a serem melhorados quanto aos parâmetros estabelecidos } \\
\text { pelo MS e MMA. }\end{array}$ & Ótima \\
B & $52-79$ & $\begin{array}{l}\text { Condições existentes chegam a atender a maioria dos itens mínimos para } \\
\text { potabilidade da água fornecida. } \\
\text { Apresenta sinais negativos preponderantes em relação ao atendimento e } \\
\text { manutenção da qualidade da água segundo os parâmetros aferidos pelo } \\
\text { MS e MMA. }\end{array}$ & $\begin{array}{c}\text { Interiária } \\
\text { (Regular) }\end{array}$ \\
D & $20-36-51$ & $\begin{array}{l}\text { Rão atende aos parâmetros de qualidade da água aferidos pelo MS e } \\
\text { MMA }\end{array}$ & Péssima \\
\hline
\end{tabular}

Fonte: Adaptado de Rocha (2008) e de ANA (2012). 


\subsection{Caracterização da amostra}

Para atender aos objetivos propostos, obtiveram-se os dados da seguinte forma: a) relatório técnico e plano de amostragem da água tratada, fornecido pela Companhia de Saneamento do Pará; b) a observação participante determinou os dados de escolaridade, renda familiar, faixa etária, ocupação empregatícia, profissão, quantitativo populacional; c) a observação sistemática determinou os dados das medidas espaciais e da infraestrutura das moradias (área dos domicílios, condições de habitação, estado de conservação das moradias, tipo de material construtivo, quantidade de BWC - banheiros com lavabo - , destinação dos rejeitos dos esgotos domiciliares) e da zona de habitabilidade urbana, com verificação direta da ocorrência de espaços públicos, disposição/afastamento dos esgotos. Nessa etapa, utilizouse uma trena convencional da marca Irwin com extensor de 30 metros, para dimensionar a área construída de cada moradia da vila habitacional União; d) utilizou-se a ferramenta digital Google Maps (2012), para dimensionar a extensão das vias de acesso localizadas na zona de habitabilidade urbana; e) cartografou-se a área de estudo elaborando-se mapas do bairro Terra Firme, em escalas de 1: 3000 e 1: 5 000, indicando o recorte espacial da área de estudo e a zona de habitabilidade urbana, utilizando-se programas gráficos.

\section{RESULTADOS E DISCUSSÃO}

O índice de qualidade ambiental urbana foi obtido com base em indicadores os quais podem ser observados na Tabela 2.

Tabela 2. Produtórios parciais e produtório final do índice de qualidade ambiental urbana.

\begin{tabular}{|c|c|c|c|c|c|c|}
\hline \multicolumn{7}{|c|}{ Índice de Qualidade Ambiental Urbana } \\
\hline Índices & $\begin{array}{l}\text { Composição dos } \\
\text { Indicadores }\end{array}$ & $\begin{array}{l}\text { Produtório } \\
\text { do Iabs }\end{array}$ & $\begin{array}{l}\text { Peso do } \\
\text { indicador }\end{array}$ & $\begin{array}{c}\text { Indicador } \\
\text { x } \\
\text { Peso }\end{array}$ & Pontuação & Nível \\
\hline $\begin{array}{l}\text { Índice de } \\
\text { abastecimento } \\
\text { de água }\end{array}$ & $I a b s=\left(\frac{26}{26}\right)$ & 1 & 15 & 15 & \multirow{5}{*}{50} & \multirow{5}{*}{ 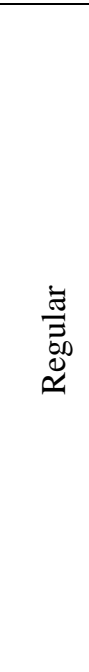 } \\
\hline $\begin{array}{l}\text { Índice de } \\
\text { cobertura } \\
\text { vegetal }\end{array}$ & $I c v=\left(\frac{0,81}{50}\right)$ & 0,0162 & 15 & 0,243 & & \\
\hline $\begin{array}{l}\text { Índice de } \\
\text { esgotamento } \\
\text { sanitário }\end{array}$ & Ies $=\left(\begin{array}{c}0+0+0,13+ \\
0,1+0,19+0 \\
1+0,5+0,4+ \\
0,2+0,1+0\end{array}\right)$ & 0.067 & 35 & 2,34 & & \\
\hline $\begin{array}{l}\text { Índice de } \\
\text { limpeza } \\
\text { pública }\end{array}$ & $I l p u=\left(\frac{26}{26}\right)$ & 1 & 20 & 20 & & \\
\hline $\begin{array}{l}\text { Índice de } \\
\text { pavimentação } \\
\text { das vias }\end{array}$ & Ipav $=\left(\frac{12350}{14875}\right)$ & 0,83 & 15 & 12,45 & & \\
\hline
\end{tabular}

O índice de habitabilidade urbana foi definido com base na Tabela 3. 
Tabela 3. Produtórios parciais dos indicadores e produtório final do índice de habitabilidade urbana da vila habitacional União.

\begin{tabular}{|c|c|c|c|c|c|c|c|c|c|c|}
\hline \multicolumn{11}{|c|}{ Índice de habitabilidade urbana } \\
\hline \multicolumn{2}{|r|}{ Indicadores } & \multirow{2}{*}{$\begin{array}{c}\begin{array}{c}\text { Variávei } \\
\text { s }\end{array} \\
A p\end{array}$} & \multirow{2}{*}{$\begin{array}{c}\text { Cálculo } \\
\left(\frac{13}{26}\right) \times 100\end{array}$} & \multirow{2}{*}{$\begin{array}{c}\text { Pontuação } \\
50\end{array}$} & $\begin{array}{c}\text { Pontua } \\
\text { ção } \\
\text { dos } \\
\text { indica } \\
\text { dores }\end{array}$ & $\begin{array}{l}\text { Compo } \\
\text { sição } \\
\text { dos } \\
\text { Indica } \\
\text { dores }\end{array}$ & \begin{tabular}{|c} 
Condiç \\
ões de \\
habitab \\
ilidade
\end{tabular} & $\begin{array}{l}\text { Composiçã } \\
\text { o dos } \\
\text { Índices }\end{array}$ & $\begin{array}{c}\text { Pontuaç } \\
\text { ão }\end{array}$ & Nível \\
\hline \multirow{5}{*}{  } & \multirow{3}{*}{$\begin{array}{l}\text { Indicador de } \\
\text { Qualidade } \\
\text { Arquitetônica }\end{array}$} & & & & \multirow{3}{*}{83,33} & \multirow{5}{*}{61,66} & \multirow{5}{*}{ 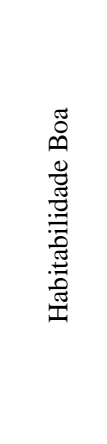 } & \multirow{18}{*}{ 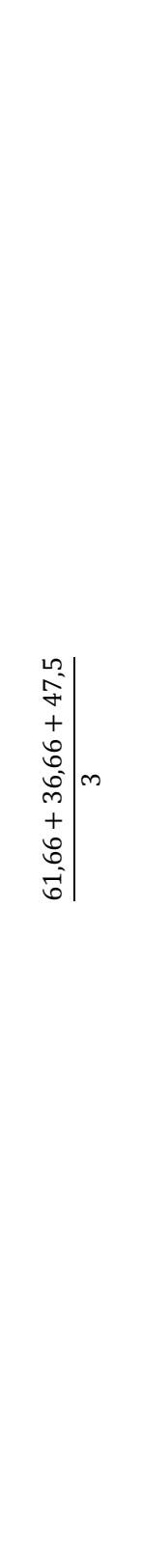 } & \multirow{18}{*}{48,6} & \multirow{18}{*}{ 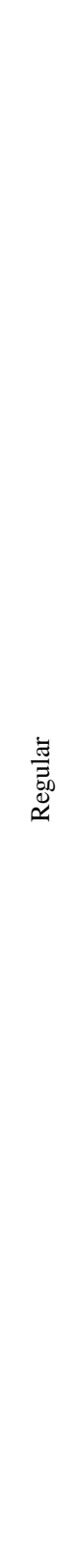 } \\
\hline & & $A g$ & $\frac{85}{41}$ & 100 & & & & & & \\
\hline & & Do & $\frac{1428}{85}$ & 100 & & & & & & \\
\hline & Indicador de & $M a$ & $\begin{array}{l}\text { Verificou- } \\
\text { se o maior } \\
\text { percentual }\end{array}$ & 50 & \multirow{2}{*}{40} & & & & & \\
\hline & $\begin{array}{l}\text { qualidade } \\
\text { Técnica }\end{array}$ & $H u$ & $\begin{array}{l}\text { Verificou- } \\
\text { se o maior } \\
\text { percentual }\end{array}$ & 30 & & & & & & \\
\hline \multirow{6}{*}{ 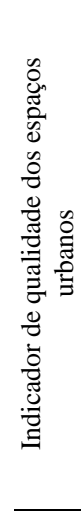 } & \multirow{2}{*}{$\begin{array}{l}\text { Indicador de } \\
\text { equipamentos } \\
\text { urbanos }\end{array}$} & Eqc & $\begin{array}{c}\text { Sem espaço } \\
\text { de uso } \\
\text { comum }\end{array}$ & 30 & \multirow{2}{*}{30} & \multirow{6}{*}{36,66} & \multirow{6}{*}{ 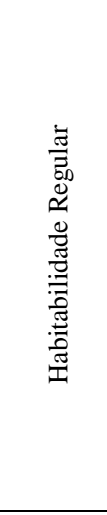 } & & & \\
\hline & & $M l$ & $\frac{0}{0}$ & 30 & & & & & & \\
\hline & Indicador de & Aup & $\left(\frac{26}{26}\right) \times 100$ & 30 & \multirow{2}{*}{30} & & & & & \\
\hline & defesa civil & $R f$ & $\left(\frac{26}{26}\right) \times 100$ & 30 & & & & & & \\
\hline & \multirow{2}{*}{$\begin{array}{c}\text { Indicador de } \\
\text { mobilidade } \\
\text { urbana e } \\
\text { acessibilidade } \\
\text { física } \\
\end{array}$} & Er & $\left(\frac{0}{145}\right) \times 100$ & 70 & \multirow{2}{*}{50} & & & & & \\
\hline & & $T c$ & $\begin{array}{c}\text { Observação } \\
\text { direta }\end{array}$ & 30 & & & & & & \\
\hline \multirow{7}{*}{ 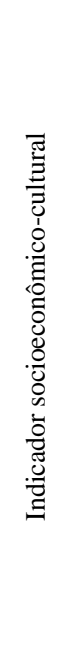 } & \multirow{3}{*}{$\begin{array}{l}\text { Indicador de } \\
\text { Educação }\end{array}$} & $A c$ & $\left(\frac{9}{9}\right) \times 100$ & 100 & \multirow{3}{*}{60} & \multirow{7}{*}{47,5} & \multirow{7}{*}{ 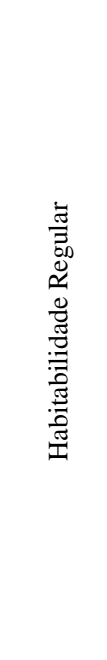 } & & & \\
\hline & & $C p$ & $\left(\frac{0}{9}\right) \times 100$ & 30 & & & & & & \\
\hline & & $E c$ & $\begin{array}{l}\text { Verificou- } \\
\text { se o maior } \\
\text { percentual }\end{array}$ & 50 & & & & & & \\
\hline & $\begin{array}{l}\text { Indicador de } \\
\text { esporte lazer }\end{array}$ & - & $\begin{array}{c}\text { Inexistência } \\
\text { de áreas de } \\
\text { esporte e } \\
\text { lazer } \\
\end{array}$ & 30 & 30 & & & & & \\
\hline & Indicador de & $M c$ & $\left(\frac{6}{26}\right) \times 100$ & 50 & 50 & & & & & \\
\hline & renda & $S c$ & $\left(\frac{23}{59}\right) \times 100$ & 50 & 30 & & & & & \\
\hline & $\begin{array}{l}\text { Indicador de } \\
\text { Saúde }\end{array}$ & - & $\begin{array}{l}\text { Equipament } \\
\text { o de saúde } \\
\text { básico }\end{array}$ & 50 & 50 & & & & & \\
\hline
\end{tabular}

O índice de qualidade da água tratada foi estabelecido com base nos dados de controle físico-químico e bacteriológico fornecidos pela Companhia de Saneamento do Pará (COSANPA), no Relatório Anual 2012, referente ao ano de 2011 (Quadro 9), que informa e esclarece as condições de tratamento da água fornecida para 767.339 pessoas, entre elas, os moradores do bairro da Terra Firme. Há, também, a demonstração dos parâmetros de qualidade desse produto, que atende às normas do artigo $9^{\circ}$ da Portaria 518, de 25 de março de 2004, do Ministério da Saúde (Quadro 11). Com esse relatório, definiu-se o índice bacteriológico e o índice físico-químico da água tratada (Tabela 4). 
Quadro 9. Painel de amostras físico-químicas e bacteriológicas da água tratada pela COSANPA/2011.

\begin{tabular}{|c|c|c|c|c|c|c|c|c|c|c|c|}
\hline \multicolumn{4}{|c|}{ Bacteriológica } & \multicolumn{8}{|c|}{ Físico-Química } \\
\hline \multirow[b]{3}{*}{$\sum_{\Sigma}^{\infty}$} & \multirow{3}{*}{ 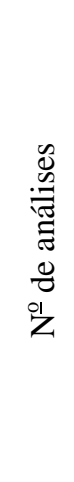 } & \multirow{3}{*}{  } & \multirow{3}{*}{ 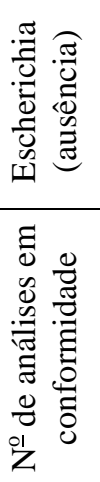 } & \multirow{2}{*}{\multicolumn{2}{|c|}{$\begin{array}{c}\text { Cor (uH) } \\
\text { Máx. } \\
\text { Permitido: } \\
5,0\end{array}$}} & \multirow{2}{*}{\multicolumn{2}{|c|}{$\begin{array}{c}\text { Turbidez (UT) } \\
\text { Máx. } \\
\text { Permitido: 5,0 }\end{array}$}} & \multirow{2}{*}{\multicolumn{2}{|c|}{$\begin{array}{c}\mathrm{CRL}(\mathrm{mg} / \mathrm{L}) \\
02 \text { a } 2,0\end{array}$}} & \multirow{2}{*}{\multicolumn{2}{|c|}{$\begin{array}{c}\text { Flúor (mg/L) } \\
\text { Máx. } \\
\text { Permitido: 1,5 }\end{array}$}} \\
\hline & & & & & & & & & & & \\
\hline & & & & 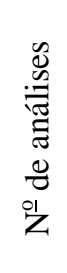 & 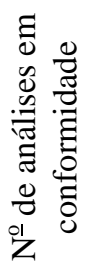 & 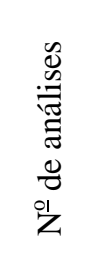 & 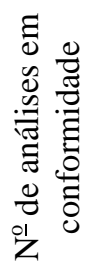 & 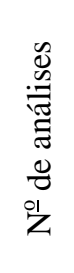 & 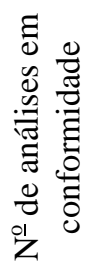 & 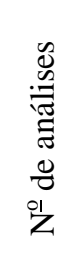 & 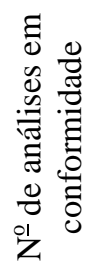 \\
\hline Jan & 65 & 63 & 65 & 65 & 61 & 65 & 64 & 65 & 57 & 31 & 31 \\
\hline $\mathrm{Fev}$ & 32 & 31 & 32 & 32 & 31 & 32 & 31 & 32 & 30 & 13 & 13 \\
\hline Mar & 29 & 28 & 29 & 29 & 27 & 29 & 29 & 29 & 29 & 15 & 15 \\
\hline Abr & 105 & 102 & 105 & 105 & 99 & 105 & 103 & 105 & 94 & 47 & 47 \\
\hline Mai & 53 & 51 & 53 & 52 & 51 & 52 & 53 & 53 & 49 & 13 & 13 \\
\hline Jun & 61 & 60 & 61 & 61 & 55 & 61 & 60 & 61 & 56 & 12 & 12 \\
\hline Jul & 78 & 77 & 78 & 78 & 76 & 78 & 77 & 78 & 77 & 6 & 6 \\
\hline Ago & 77 & 75 & 77 & 77 & 776 & 77 & 77 & 77 & 71 & 28 & 28 \\
\hline Set & 75 & 73 & 75 & 75 & 73 & 75 & 75 & 75 & 70 & 13 & 13 \\
\hline Out & 85 & 82 & 85 & 85 & 83 & 85 & 84 & 85 & 80 & 38 & 38 \\
\hline Nov & 79 & 79 & 79 & 79 & 77 & 79 & 77 & 79 & 73 & 35 & 35 \\
\hline Dez & 110 & 110 & 110 & 110 & 108 & 110 & 108 & 110 & 106 & 50 & 50 \\
\hline Total & 849 & 831 & 849 & 848 & 817 & 848 & 837 & 849 & 792 & 301 & 301 \\
\hline
\end{tabular}

Fonte: COSANPA (2012).

O plano de amostragens da água definido pela empresa de abastecimento de água de Belém, (Quadro 10), e o plano de amostras determinado pela Portaria do Ministério da Saúde (2004), (Quadro 11) foram relacionados para determinar o Índice de Coleta da água (Tabela 4).

Quadro 10. Plano de Amostragem conforme Portaria do MS no 518/2004 aplicado pela COSANPA.

\begin{tabular}{|ccccc|}
\hline Parâmetro & \multicolumn{2}{c}{ Saída do Tratamento } & \multicolumn{2}{c|}{ Rede de distribuição } \\
\hline № de amostras & $\begin{array}{c}\mathrm{N}^{\mathrm{o}} \text { de } \\
\text { amostras }\end{array}$ & Frequência & $\begin{array}{c}\text { № de } \\
\text { amostras }\end{array}$ & Frequência \\
\hline Cor, turbidez, $\mathrm{pH}$ & 360 & Mensal & 71 & Mensal \\
Cloro residual & 360 & Mensal & 258 & Mensal \\
Flúor & 360 & Mensal & 35 & Mensal \\
Coliformes totais & 8 & Mensal & 258 & Mensal \\
Demais parâmetros & 1 & Semestral & 1 & Semestral \\
\hline
\end{tabular}

Fonte: COSANPA (2012). 
Quadro 11. Número mínimo de amostras para o controle da qualidade da água de sistema de abastecimento segundo Portaria do MS/2004.

\begin{tabular}{|c|c|c|c|c|c|}
\hline \multirow{4}{*}{$\begin{array}{c}\text { Tipo de } \\
\text { Manancial }\end{array}$} & \multirow{4}{*}{ Parâmetro } & \multicolumn{4}{|c|}{ Legislação Vigente (Portaria № 518/GM em 25 de março de 2004) } \\
\hline & & \multicolumn{4}{|c|}{ Sistema de Distribuição (Pop. > 250.000 hab.) } \\
\hline & & \multicolumn{2}{|c|}{ Reservatórios e Rede } & \multicolumn{2}{|c|}{ Saída do Tratamento } \\
\hline & & $\mathrm{N}^{\mathrm{o}}$ de amostras & Frequência & $\begin{array}{c}\mathrm{N}^{\circ} \mathrm{de} \\
\text { amostras }\end{array}$ & Frequência \\
\hline \multirow{5}{*}{ Superficial } & Cor, Turbidez, $\mathrm{pH}$ & 71 & Mensal & 360 & Mensal \\
\hline & Coliformes totais & 258 & Mensal & 8 & Mensal \\
\hline & CRL & 258 & Mensal & 360 & Mensal \\
\hline & Flúor & 35 & Mensal & 360 & Mensal \\
\hline & Demais Parâmetros & 1 & Semestral & 1 & Semestral \\
\hline
\end{tabular}

Fonte: Ministério da Saúde (Brasil, 2004).

Tabela 4. Produtório parcial dos indicadores e produtório do índice de qualidade da água tratada pela COSANPA.

\begin{tabular}{|c|c|c|c|c|c|}
\hline \multicolumn{6}{|c|}{ Índice de qualidade da água tratada } \\
\hline \multirow{2}{*}{ Indicadores } & \multirow{2}{*}{ Equação dos indicadores } & \multirow{2}{*}{$\begin{array}{l}\text { Produtório dos } \\
\text { indicadores }\end{array}$} & \multirow{2}{*}{$\begin{array}{l}\text { Composição dos } \\
\text { Indicadores }\end{array}$} & \multicolumn{2}{|c|}{ IQAT } \\
\hline & & & & Valor & Nível \\
\hline Índice de Coleta & $\left(\frac{623}{623}\right) \times 100$ & 100 & & & \\
\hline Índice & $\left(\frac{831}{80}\right) \times 100$ & 97,87 & $(100+97,87+96,52)$ & 9813 & Ótimo \\
\hline Bacteriologico & $(849)$ & & 3 & 90,13 & Uimo \\
\hline $\begin{array}{l}\text { Índice Físico- } \\
\text { químico }\end{array}$ & $\left(\frac{817+837+792+301}{848+848+849+301}\right) \times 100$ & 96,52 & & & \\
\hline
\end{tabular}

Na Tabela 5 observa-se a composição dos 3 índices macros do índice de qualidade ambiental urbana integrada (IQAUI).

Tabela 5. Produtório do índice qualidade ambiental urbana integrada da vila habitacional União.

\begin{tabular}{|c|c|c|c|c|c|}
\hline \multicolumn{6}{|c|}{ Índice de qualidade ambiental urbana integrada } \\
\hline \multirow{2}{*}{ Índices } & \multirow{2}{*}{ Nível } & \multirow{2}{*}{ Pontuação } & \multirow{2}{*}{ Composição dos Índices } & \multicolumn{2}{|c|}{ IQAUI } \\
\hline & & & & Pontuação & Nível \\
\hline $\begin{array}{l}\text { Índice de qualidade } \\
\text { ambiental urbana }\end{array}$ & Regular & 50 & \multirow{4}{*}{$\left(\frac{50+48,6+98,13}{3}\right)$} & \multirow{4}{*}{65,57} & \multirow{4}{*}{ Bom } \\
\hline Índice de habitabilidade & Regular & 48,6 & & & \\
\hline urbana & Keguial & 40,0 & & & \\
\hline $\begin{array}{l}\text { Índice de qualidade da água } \\
\text { tratada }\end{array}$ & Ótimo & 98,13 & & & \\
\hline
\end{tabular}

O índice de qualidade ambiental urbana integrada atingiu 65,57 na escala de avaliação, caracterizando padrão bom. Essa padronização aponta para a relativa qualidade ambiental urbana da vila habitacional União, revelando sensível melhoria na qualidade de vida da população residente nessa unidade socioterritorial.

O esgotamento sanitário indicou nível crítico, e a deficiência nesse serviço implica prejuízos ao ambiente, à saúde e ao bem-estar da população (Dias, 2011). A inexistência desta infraestrutura urbana, por sua vez, contribui para o aumento da degradação dos mananciais de água (superficiais e subterrâneos) e, consequentemente, compromete a saúde da população 
(Soares et al., 2005). Esse ditame negativo na qualidade ambiental urbana impõe, à população da periferia, a construção de alternativas sanitárias para despejo de seus efluentes domésticos, valendo-se de fossas rudimentares, valas, rios ou outro mecanismo ejetor de rejeitos domésticos.

A baixa incidência de arborização impõe péssimas condições térmicas à zona de habitabilidade urbana, pois a temperatura à sombra reduz poucos graus em relação à condição de se estar recebendo radiação direta do sol, mas sente-se conforto, por não se receber radiação direta. Deve-se entender que a própria arborização de vias pode abrandar o processo de aquecimento, em virtude da capacidade que a vegetação tem de interceptar a radiação solar (Schuc, 2006). Para amenizar esse cenário arbóreo deficitário da zona de habitabilidade urbana, os moradores plantam árvores no quintal ou na frente da casa, produzindo um sistema arbóreo inconsistente, disperso e quase que ineficaz para a manutenção do bioclima da zona de habitabilidade urbana.

A pavimentação das vias de acesso à vila habitacional União representa avanço na qualidade de vida da população, que trafega a pé ou em veículo, por um ambiente com melhor mobilidade urbana, particularmente porque há alguns anos se caminhava por pontes que eram as únicas vias de acesso a outras unidades da cidade.

$\mathrm{Na}$ habitabilidade urbana os indicadores mais críticos foram os aspectos técnicos da moradia, conservação do imóvel, integração dos banheiros aos imóveis e a acessibilidade, que determinam a baixa habitabilidade urbana da vila habitacional União. Os indicadores socioeconômicos mostraram-se melhores, quanto à educação, renda, empregabilidade e mobilidade, apontando um grau de habitabilidade urbana maior.

A avaliação boa do IQAUI, aplicada à vila habitacional União, corresponde às múltiplas ações do poder público nos últimos anos na Terra Firme, com pavimentação, retificação de canais, iluminação pública, saneamento básico, implantação de postos de saúde. No entanto, essa ação não é suficiente, se não acompanhada por políticas de estruturação social que suplantem a identidade físico-social da favela, especificada pelo grande contingente populacional pauperizado, moradias precárias ou inadequadas, déficit habitacional, baixa remuneração do trabalhador, baixos índices de escolaridade.

Os três índices integrados possibilitaram investigar mais detalhadamente a unidade socioterritorial intraurbana denominada de vila habitacional União, como representante de uma realidade mais ampla da cidade. Assim, essa modelagem de indicadores representa a possibilidade do uso de uma importante ferramenta nas análises da qualidade ambiental urbana, em micro ou em macro escala.

Os indicadores, quando aplicados isoladamente, podem superdimensionar um problema, como a qualidade técnica das moradias, que se demonstrou em nível crítico, ou superestimar a qualidade dos serviços ou dos equipamentos urbanos, como o transporte coletivo, que apresentou nível bom. Sendo assim, recomenda-se não analisar os indicadores de qualidade ambiental urbana integrada isoladamente (Santos e Martins, 2002).

A modelagem de indicadores de qualidade ambiental urbana mostrou-se vantajosa no que se refere a sua variedade e amplitude de análises do espaço intraurbano em microescala de forma integrada, podendo-se propor mais eficientes relações de gestão ambiental e reestruturação do ambiente das cidades, principalmente nas periferias (Borja, 1998).

\subsection{Simulação e formulação de cenário de qualidade ambiental urbana integrada: abordagem dos problemas socioambientais}

$\mathrm{Na}$ Tabela 6, foram considerados apenas os indicadores que apresentaram avaliação regular e crítica/péssima, para definir um parâmetro de qualidade ambiental da vila habitacional União, simulando um cenário ambiental que reflita a necessidade de melhorias dos problemas mais agudos desse micro-espaço urbano. 
Tabela 6. Simulação do índice de qualidade ambiental urbana integrada.

Índice de Qualidade Ambiental Urbana Integrada

\begin{tabular}{|c|c|c|c|c|c|c|c|c|}
\hline & & Indicadore & & : & 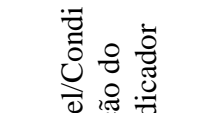 & : & 胥 & 迶 \\
\hline 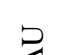 & & Índice de cober & ra vegetal & 0,243 & & & & \\
\hline$=$ & & Índice esgotame & o sanitário & 2,34 & & & & \\
\hline & 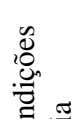 & $\begin{array}{l}\text { Indicador de } \\
\text { Qualidade } \\
\text { Arquitetônica }\end{array}$ & $\begin{array}{c}\text { Adequação } \\
\text { projetual }\end{array}$ & 50 & Regular & 50 & & \\
\hline & $\underbrace{0}_{i=1}$ & & Material adequado & $\begin{array}{c}89,74 \% \text { de } \\
\text { madeira }\end{array}$ & Regular & 50 & & \\
\hline & 苞 & qualidade Técnica & $\begin{array}{l}\text { Presença de sinais } \\
\text { de umidade e/ou } \\
\text { rachaduras }\end{array}$ & $\begin{array}{c}\text { Excesso de } \\
\text { sinais de } \\
\text { umidade }\end{array}$ & Crítica & 30 & & \\
\hline & $\stackrel{\infty}{g}$ & Indicador de & $\begin{array}{l}\text { Equipamentos de } \\
\text { uso comum (Centro } \\
\text { comunitário) }\end{array}$ & 0 & Crítica & 0 & & \\
\hline & $\begin{array}{l}0 \\
\vdots \\
0 \\
0 \\
0 \\
\tilde{0} \\
0 \\
0\end{array}$ & $\begin{array}{l}\text { equipamentos } \\
\text { urbanos }\end{array}$ & $\begin{array}{c}\text { Manutenção e } \\
\text { limpeza dos espaços } \\
\text { e equipamentos de } \\
\text { uso comum }\end{array}$ & 0 & Crítica & 0 & & \\
\hline & 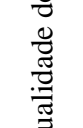 & Indicador de & $\begin{array}{l}\text { Unidades sem } \\
\text { acesso a serviços de } \\
\text { utilidade pública }\end{array}$ & 100 & Crítica & 30 & & \\
\hline & 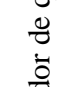 & & $\begin{array}{c}\text { Unidades em área } \\
\text { de risco }\end{array}$ & 100 & Crítica & 30 & ते. & 奉 \\
\hline 冬 & : & $\begin{array}{c}\text { Indicador de } \\
\text { mobilidade } \\
\text { urbana e } \\
\text { acessibilidade } \\
\text { física } \\
\end{array}$ & $\begin{array}{l}\text { Existência de } \\
\text { rebaixamento das } \\
\text { guias de calçadas } \\
\text { em travessias }\end{array}$ & 0 & Crítica & 0 & & \\
\hline & & Indicador de & $\begin{array}{c}\text { Acesso de jovens de } \\
15 \text { a } 17 \text { anos a } \\
\text { programas de } \\
\text { profissionalização }\end{array}$ & 0 & Crítica & 0 & & \\
\hline & 蹗 & & $\begin{array}{l}\text { Escolaridade do } \\
\text { chefe de família }\end{array}$ & $\begin{array}{l}57 \% \text { ens. } \\
\text { médio } \\
\text { completo }\end{array}$ & Regular & 50 & & \\
\hline & 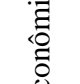 & $\begin{array}{l}\text { Indicador de } \\
\text { esporte lazer }\end{array}$ & - & 0 & Crítica & 0 & & \\
\hline & $\begin{array}{l}: \\
0 \\
0 \\
\dot{0} \\
\bar{g}\end{array}$ & Indicador de & $\begin{array}{l}\text { Domicílios com } \\
\text { mulher chefe de } \\
\text { família }\end{array}$ & 23 & Regular & 50 & & \\
\hline & 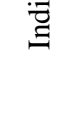 & emprego e renda & $\begin{array}{l}\text { Situação } \\
\text { empregatícia da } \\
\text { família }\end{array}$ & 38,98 & Regular & 50 & & \\
\hline & & $\begin{array}{l}\text { Indicador de } \\
\text { Saúde }\end{array}$ & - & 1 & Regular & 50 & & \\
\hline
\end{tabular}


O produtório crítico/péssimo do indicador de arborização, 0.243 , indica um gradiente de desequilíbrio térmico na zona de habitabilidade urbana da vila habitacional União, configurando baixa volatilidade das massas de ar que amenizam a sensação térmica, além da filtração dos gradientes de dióxido de carbono, o que melhoraria a qualidade do ar. A baixa incidência arbórea impede que haja um bom desempenho nas várias funções que a vegetação urbana apresenta para a melhoria da qualidade ambiental adequada e agradável à convivência humana (Resende e Souza, 2009).

Essa dimensão ambiental da zona de habitabilidade urbana, arborização, confronta-se com a faixa percentual recomendável em arborização nas cidades, para o adequado balanço térmico nas áreas urbanas, que está em torno de $30 \%$ e, em áreas onde o índice de arborização é inferior, 5\%, as características climáticas assemelham-se às de regiões desérticas (Rodrigues e Luz, 2007).

$\mathrm{O}$ indicador de esgotamento sanitário atingiu escala de 2.34. Esse padrão avaliativo determina que a qualidade de vida da população da vila habitacional União apresenta declínio, por não terem acesso ao sistema de esgotos sanitários, de forma a garantir a coleta, o transporte, o tratamento e a disposição ambientalmente adequada e sanitariamente segura dos efluentes domésticos. Assim, os moradores estão expostos a potenciais doenças relacionadas à carga poluidora dos esgotos sanitários (Brasília, 2004).

Os sistemas de saneamento são também diretamente relacionados com a proteção do meio ambiente e com o desenvolvimento urbano (Soares et al., 2005). A zona de habitabilidade urbana da vila habitacional União está entre os microambientes intraurbanos de baixo desenvolvimento, contribuindo para o aumento da degradação dos mananciais de água e, consequentemente, para a elevação dos custos com o tratamento da água, em Belém.

A adequação projetual dos domicílios da vila habitacional União apresentou escala regular, destacando-se que, na metade dos domicílios, os banheiros não estão integrados. Isso representa potenciais riscos à saúde dos moradores, que podem contrair doenças diarreiogênicas ou de outra natureza infecciosa.

A presença de sinais de umidade mostrou-se crítica, potencializando a formação de mofo no interior da habitação, em paredes, teto, tapetes, sujeitando os residentes, especialmente as crianças, ao desenvolvimento de doenças respiratórias (Fiório, 2009).

A não existência de equipamentos de uso comum no Centro Comunitário limita as ações desse grupo populacional, pois se acredita que essa forma de organização social molda uma estrutura onde se desenvolvem ações tão diversificadas quanto as necessidades sentidas pela população, configurando uma modalidade social integrada e global de responder aos problemas das pessoas e das famílias (Bonfim et al., 2000).

A condição crítica do acesso a serviços de utilidade pública dos moradores da vila habitacional União constitui um sério obstáculo ao desenvolvimento humano desses moradores, haja vista ser fundamental para se levar uma vida digna, bem como o acesso eficaz aos serviços de utilidade pública, fator que constitui exigência para uma qualidade de vida satisfatória (Hailu e Hunt, 2008).

A vila habitacional União encontra-se em área de risco de alagamentos, definindo indicador com avaliação crítica, visto que moradias em áreas de riscos de inundação provocam impactos sociais relevantes. Os principais impactos sobre a população são: prejuízos de perdas materiais e humanas; interrupção da atividade econômica das áreas atingidas, gerando ônus para a região; e contaminação por doenças de veiculação hídrica (Barbosa, 2006).

$\mathrm{O}$ indicador de acessibilidade revelou avaliação crítica, constituindo-se como mais um fator limitador da qualidade ambiental urbana da zona de habitabilidade da vila habitacional União, tendo em vista que a acessibilidade nas estruturas das cidades passa a ser um insumo indispensável para o planejamento das políticas públicas, como qualidade adicional do 
entorno urbano, vista e sentida de forma conjunta na globalidade do ambiente e suas interrelações. São necessários espaços, produtos bens de serviços, objetos e instrumentos, dispositivos ou ferramentas, para utilização por todas as pessoas (Fonseca, 2009).

$\mathrm{O}$ indicador crítico do acesso de jovens a cursos profissionalizantes impõe maior fragilidade desse grupo populacional à formação técnica profissionalizante, compondo mais um fator negativo na busca de capacitação profissional dos jovens, constituindo um futuro óbice para absorção mais qualificada para o mercado de trabalho e para o potencial desenvolvimento socioeconômico (Cruz, 1999).

A baixa avaliação dos indicadores de qualidade ambiental urbana da vila habitacional União expressa as deficiências e desequilíbrios apontados nas variáveis analisadas, os quais indicam forte pressão sobre a qualidade de vida da população residente nessa unidade socioterritorial, que está exposta a condições socioambientais negativas, mensuradas neste trabalho pelo índice de qualidade ambiental urbana integrada.

\section{CONCLUSÃO}

Conclui-se que a modelagem de indicadores de qualidade ambiental urbana integrada representa a possibilidade do uso de uma importante ferramenta nas análises da qualidade ambiental urbana, em micro ou em macro escala, propondo-se relações de gestão e reestruturação mais eficientes do ambiente urbano, principalmente nas periferias.

As limitações na abordagem metodológica encontram-se no quadro da escala de avaliação. No caso do índice de habitabilidade urbana, há fragilidade no campo mensurador do nível crítico pois, mesmo que um indicador apresente resultado zero, sua pontuação se manterá na linha numérica de 30 pontos. Há, assim, um mascaramento das condições críticas dos indicadores interferindo na precisão do produtório final do índice de qualidade ambiental urbana integrada. Por isso, houve a proposição de uma simulação da qualidade ambiental da vila habitacional União.

Os indicadores de qualidade ambiental urbana apontaram componentes críticos, como a arborização, o esgotamento sanitário, os equipamentos urbanos, o esporte e lazer, a qualidade arquitetônica, os equipamentos urbanos, o acesso de jovens a programas de profissionalização. No entanto, ao serem agregados aos indicadores com avaliação elevada, como limpeza pública, pavimentação de vias, abastecimento de água, bem como a integração ao macro índice de qualidade da água tratada, com avaliação ótima, resultaram no índice de qualidade ambiental urbana integrada da vila habitacional União com nível bom, expondo relativa melhoria na qualidade de vida dos moradores da vila habitacional União, seja pela oferta de bons serviços públicos, seja pelo crescimento em seu quadro socioeconômico.

\section{REFERÊNCIAS}

AGÊNCIA NACIONAL DAS ÁGUAS - ANA (Brasil). Portal da Qualidade das Águas. Índice de qualidade das águas. Disponível em: <http://pnqa.ana.gov.br/IndicadoresQA/IndiceQA.aspx>. Acesso em: 04 jun. 2012.

BARBOSA, F. de A. dos R. Medidas de proteção e controle de inundações urbanas na bacia do rio Mamanguape/PR. 2006. 113f. Dissertação (Mestrado em Engenharia Urbana) - Universidade Federal da Paraíba, João Pessoa, 2006. Disponível em: <http://www.cprm.gov.br/publique/media/diss_franciscobarbosa.pdf〉. Acesso em: 11 abr. 2013.

BONFIM, C. de J. et al. Centro comunitário. Lisboa: Núcleo de Documentação Técnica e Documentação, 2000. Disponível em: <http://www4.seg-social.pt/documents/ 10152/13331/Centro_comunitario>. Acesso em: 11 abr. 2013. 
BORJA, P. C. Metodologia para a avaliação da qualidade ambiental urbana em nível local. Artigo. In: CONGRESSO INTERAMERICANO DE ENGENHARIA SANITÁRIA E AMBIENTAL, 26., 1998, Lima. Anais eletrônicos... Disponível em: <http://www.bvsde.paho.org/bvsaidis/ impactos/peru/braiaa222.pdf >. Acesso em: 01 abr. 2012.

BRASIL. Ministério da Saúde. Secretaria de Vigilância em Saúde. Diretriz nacional do plano de amostragem da vigilância em saúde ambiental relacionada à qualidade da água para consumo humano/Ministério da Saúde, Secretaria de Vigilância em Saúde. - Brasília: Ministério da Saúde, 2006. 60 p. - (Série A. Normas e Manuais Técnicos).

BRASIL. Secretaria de Assuntos Estratégicos. Comissão para definição da classe média no Brasil. Brasília, 2012. Disponível em: <http://www.sae.gov.br/site/wpcontent/uploads/Relat\%C3\%B3rio-Defini\%C3\%A7\%C3\%A3o-da-Classe-

M\%C3\%A9dia-no-Brasil.pdf>. Acesso em: 14 set. 2012.

BRASIL. Ministério da Saúde. Portaria no 518/GM em 25 de março de 2004. Disponível em: <http://dtr2001.saude.gov.br/sas/PORTARIAS/Port2004/GM/GM-518.htm>. Acesso em: 19 ago. 2012.

BRASIL. Ministério da Integração Nacional. BRASÍLIA. Projeto de gerenciamento integrado das atividades desenvolvidas em terra na bacia do São Francisco ANA/GEF/PNUMA/OEA. Estudo Técnico de Apoio ao PBHSF - No 03. Brasília, 2004. Disponível em: 〈www.mi.gov.br/download/download.asp?endereco=/...12...〉. Acesso em: 01 jul. 2012.

COMPANHIA DE SANEAMENTO DO PARÁ - COSANPA. Relatório anual de amostras físico-químicas e bacteriológicas da água tratada. Belém, 2012.

CRUZ, P. N. da. A importância do papel do ensino profissionalizante face ao processo de industrialização de Juiz de Fora. Caderno de Pesquisa em Administração, São Paulo, v. $1, \quad \mathrm{n}, \quad 8,1^{\mathrm{o}}$ trim. 1999. Disponível em: <http://www.ead.fea.usp.br/cadpesq/arquivos/c8-Art4.pdf>. Acesso em: 11 abr. 2013.

DIAS, F. de A. Caracterização e análise da qualidade ambiental urbana da bacia do Ribeirão do Lipa, Cuiabá/MT. 2011. 132 f. Dissertação (Mestrado em Eng. De Edificações e Ambiental) - Universidade Federal do Mato Grosso, Cuiabá, 2011. Disponível em: $<$ http://pt.scribd.com/doc/86894066/Avaliacao-da-Qualidade-ambientalurbana-da-bacia-do-Ribeirao-do-Lipa>. Acesso em: 25 abr. 2012.

FIÓRIO, C. E. Mofo nos domicílios dos recém-nascidos de uma coorte da cidade de São Paulo, Brasil - Projeto Chiado. 2009. 101f. Dissertação (Mestrado em Saúde pública) - Universidade de São Paulo, São Paulo, 2009. Disponível em: <www.teses.usp.br/teses /disponiveis/6/6132/tde.../CleitonFiorio.pdf $>$. Acesso em: 11 abr. 2013.

FLORIANÓPOLIS. Prefeitura Municipal. Monitoramento das ações da política habitacional de Florianópolis. Relatório Final. Produto 4. Florianópolis, 2007. Disponível

em: <http://portal.pmf.sc.gov.br/arquivos/arquivos/pdf/18_06_2010_15.57.20.b9133eaa67ddce377186208e1a cc33e5.pdff>. Acesso em: 09 ago. 2012.

FONSECA, L. A. de M. Acessibilidade, um problema nas grandes cidades. Manaus, 2009. Disponível em: 〈http://www.seplan.am.gov.br/arquivos/download/arqeditor/artigo_06.pdf〉. Acesso em: 11 abr 2013. 
HAILU, D.; HUNT, P. Fornecimento de serviços de utilidade pública: desenho dos contratos, no interesse dos pobres. Centro Internacional de Políticas para o Crescimento Inclusivo. $\mathrm{n}^{\mathrm{o}}$ 10. Dez/2008. Disponível em: <http://www.ipcundp.org/pub/port/IPCPolicy ResearchBrief10.pdf>. Acesso em: 11 abr. 2013.

KOHARA, L. T. Relação entre as condições da moradia e o desempenho escolar: estudo com crianças residentes em cortiços. 2009. 297f. Tese (Doutorado em Arquitetura e Urbanismo) - Universidade de São Paulo, São Paulo, 2009. Disponível em: <http://www.gaspargarcia.org.br/Administrativo/secure/arquivos/publicacoes/19320121 0320363.pdf>. Acesso em: 09 maio 2012.

MINAKI, C.; AMORIM, M. C. de C. T. Espaços urbanos e qualidade ambiental - um enfoque da paisagem. Revista Formação, v. 1, n. 14, p. 67-82, 2007. Disponível em: <http://www4.fct.unesp.br/pos/geo/revista/artigos/Minaki.pdf>. Acesso em: 05 jan. 2012.

MORAES, L. R. S.; SANTOS, M. E. P. dos; SAMPAIO, R. M. Indicadores da qualidade ambiental urbana: a experiência do Dique de Campinas em Salvador, Bahia. Revista de Urbanismo e Arquitetura, v. 7, n. 1, 2006. Disponível em: <LRS Moraes, MEP Santos... - Revista de Urbanismo e ..., 2008 - portalseer.ufba.br>. Acesso em: 10 set. 2012.

MORATO, R. G. Análise da qualidade de vida urbana no município de Embu/SP. 2004. 117f. Dissertação (Mestrado em Geografia Física) - Universidade de São Paulo, São Paulo, 2004. Disponível em: <http://dspace.universia.net/bitstream/2024/101/1/mestrado-rubia.PDF>. Acesso em: 02 maio 2012.

NAHAS, M. I. P. Metodologia de construção de índices e indicadores sociais, como instrumentos balizadores da gestão municipal da qualidade de vida urbana: uma síntese da experiência de Belo Horizonte. Anais. In: SEMINÁRIO SOBRE INDICADORES DE SUSTENTABILIDADE. PRONEX-NEPO/UNICAMP, 2000, Campinas. Disponível em: <www.nepo.unicamp.br/.../

POLLI, S. A. Curitiba, metrópole corporativa: fronteiras da desigualdade.2006. 178f. Dissertação (Mestrado em Planejamento Urbano e Regional) - Universidade Federal do Rio de Janeiro - UFRJ, Rio de Janeiro, 2006. Disponível em: <http://teses.ufrj.br/IPPUR_M/Simone AparecidaPolli.pdf>. Acesso em: 01 abr. 2012.

RESENDE, W. X.; SOUZA, H. T. R. de. Índices de áreas verdes públicas: uma avaliação fitogeográfica da qualidade ambiental em Aracaju. In: SIMPÓSIO BRASILEIRO DE GEOGRAFIA FÍSICA APLICADA, 13., 2009, Viçosa. Anais... Disponível em: <www.geo.ufv.br/simposio/simposio/trabalhos/trabalhos.../025.pdf>. Acesso em: 02 ago. 2012.

ROCHA, J. L. S. Indicador integrado de qualidade ambiental, aplicado à gestão da Bacia Hidrográfica do Rio Jiquiriçá - BA. 2008. 99f. Dissertação (Mestrado em Desenvolvimento e Meio Ambiente) - Universidade Estadual de Santa Cruz, Ilhéus, 2008.

em: <http://www.uesc.br/cursos/pos_graduacao/mestrado/mdrma/teses/dissertacao_jadson_1 uiz.pdf>. Acesso em: 03 abr. 2012. 
RODRIGUES, J. E. C.; LUZ, L. M. da. Mapeamento da cobertura vegetal da área central do município de Belém PA, através de sensores remotos de base orbital (sensor TM, LANDSAT 5 e sensor CCD, CBERS 2). In: SIMPÓSIO BRASILEIRO DE SENSORIAMENTO REMOTO, 13., 21-26 abril 2007, Florianópolis. Anais... São José dos Campos: INPE, 2007. p. 1063-1070. Disponível em: <marte.dpi.inpe.br/col/dpi.inpe.br/sbsr@80/ 2006/.../1063-1070.pdf>. Acesso em: 02 ago. 2012.

SANTOS, L. D.; MARTINS, I.. A qualidade de vida urbana: o caso da cidade do Porto. WorkingPapers da FEP. Investigação - Trabalhos em curso - n ${ }^{\circ}$ 116, Maio de 2002. Disponível em: <http://wps.fep.up.pt/wps/wp116.pdf>. Acesso em: 04 abr. 2012.

SCHUCH, M. I. S. Arborização urbana: uma contribuição a qualidade de vida com uso de geotecnologias. 2006. 102f. Dissertação (Mestrado em Geomática) -Universidade de Federal de Santa Maria, Santa Maria, 2006. Disponível em: <http://cascavel.cpd.ufsm.br/tede/tde_arquivos/21/TDE-2007-08-21T144753Z769/Publico/Mara\%20Ione.pdf>. Acesso em: 06 ago. 2012.

SOARES, J. M. et al. Alternativas de traçado da rede coletora de esgoto sanitário e custos de construção. In: CONGRESO REGIONAL IV REGIÓN, 5., 23-25 Mayo 2005, Asunción, Disponível em: <http://www.bvsde.paho.org/bvsaidis/paraguay5/IIAS14.pdf>. Acesso em: 01 ago. 2012.

SOARES FILHO, B. S. Análise de paisagem: fragmentação e mudanças. Belo Horizonte: UFMG, 1998. Disponível em: <http://www.csr.ufmg.br/csr/publicacoes/apostila.pdf>. Acesso em: 06 ago. 1998. 